Ks. Andrzej UCIECHA*

\title{
PATRIARCHAT I PATRIARCHOWIE SELEUCJI-KTEZYFONTU. Z DZIEJÓW STAROŻYTNEGO KOŚCIOLA W PERSJI
}

Seleucja (syr. Slyk) to miasto założone w IV w. prz. Chr. nad Tygrysem przez Seleukosa I Nikator (353-281 prz. Chr.), ośrodek życia kulturalno-społecznego i przez pewien czas stolica monarchii Seleucydów, a później miasto królewskie Sasanidów (30 km na południowy-wschód od Bagdadu). Miasto nazywane jest również Miasta (syr. Mahozê) i Dwa Miasta (w Synodicon Orientale); inna nazwa oficjalna Beh (Veh)-Ardašîr pochodzi od perskiego króla Ardaszyra I (224/226-241) z dynastii Sasanidów, który stłumił powstanie Partów w 224 r., Seleucję zaś przebudował i nazwał „dobre miasto Ardaszira”.

$\mathrm{Na}$ drugim brzegu rzeki leżało miasto Opis, które wkrótce stało się jej przedmieściem. Partowie po opanowaniu Mezopotamii (129 r. prz Chr.) na miejscu Opis założyli Ktezyfont, zwany przez nich Tyspon, który wraz z Seleucją stał się jednym z największych miast starożytnego świata (ok. 30 $\mathrm{km}^{2}$ powierzchni). Ktezyfont, stolica Partii, od $226 \mathrm{r}$. wchodząca w skład państwa perskiego, leży na lewym wschodnim brzegu Tygrysu, w miejscu, w którym rzeka ta najbardziej zbliża się do Eufratu. Odległość pomiędzy korytami obu rzek w miejscu największego ich zbliżenia wynosiła nieco ponad $40 \mathrm{~km}^{1}$.

Sokrates Scholastyk (ok. 380-ok. 450) przedstawia Ktezyfont jako olbrzymie miasto, najprawdopodobniej potężnie umocnione (otoczone murami w połowie I w. za króla Pakorusa II $-78-105)^{2}$. O Ktezyfoncie wspomina również Hermiasz Sozomen (ok. 400-450) w swojej Historii Kościoła jąc prześladowania chrześcijan w Persji za panowania Szapura II (309-379), najpierw, gdy mówi o męczeństwie biskupów Seleucji i Ktezyfontu, Symeona

* Ks. dr hab. Andrzej Uciecha - adiunkt w Zakładzie Teologii Patrystycznej i Historii Kościoła na Wydziale Teologicznym Uniwersytetu Śląskiego w Katowicach; e-mail: andrzej.uciecha@wp.pl.

1 Por. komentarz A. Ziółkowskiego w: Hermiasz Sozomen, Historia Kościoła, tłum. S. Kazikowski, Warszawa 1980, 351, przyp. 4 i 5.

${ }^{2}$ Por. Socrates, HE III 21, 4, SCh 493, 326, thum. S. Kazikowski: Sokrates Scholastyk, Historia Kościoła, Warszawa 1986, 310-311.

${ }^{3}$ Hermiasz Sozomen pisał swoje dzieło między 439 a 450 r., por. Z. Zieliński, Wstęp, w: Hermiasz Sozomen, Historia Kościoła, s. 12-13. 
$(† 341)^{4}$ i Barbasymasa $(† 346)^{5}$ a następnie wprost, gdy opisuje wyprawę wojenną cesarza Juliana przeciwko Persom w 363 roku:

„co tylko zajął, niszczył i pustoszył do szczętu; spichlerze i wszelkie inne budowle częściowo burzył równając je z ziemią, częściowo zaś palił. Ciągnąc szlakiem wzdłuż Eufratu dotarł tuż pod Ktezyfont. Jest to miasto ogromne i zastępuje Babilon mieszcząc w swym obrębie siedzibę perskich monarchów, a niedaleko od niego przepływa rzeka Tygrys. Wobec tego, że na okrętach nie można było podejść do Ktezyfontu, z powodu lądu, jaki dzielił obie rzeki, i trzeba było albo minąc to miasto, albo też zostawić flotyllę swojemu losowi”.

Wyrażenie,,Seleucja-Ktezyfont”wydaje się byćnieznane zarówno Sokratesowi Scholastykowi, jak i Hermiaszowi Sozomenowi.

Ktezyfont (Ktesiphon; obecnie El-Madain, ruiny Takti-Kešra) jako stolica Persji był wielokrotnie zdobywany przez Rzymian (165-166, 197 i 216) ${ }^{7}$. W 283 r. perską stolicę zdobył cesarz Karus $(282-283)^{8}$, w 298 r. Galeriusz (293-311), cezar cesarza Dioklecjana (284-305)9, w 627 r. Ktezyfont złupiły bizantyjskie wojska Herakliusza (610-641). W 637 r. Ktezyfont został zdobyty i splądrowany przez Arabów, którzy przemianowali bliźniacze miasta na AlMadain (Miasta).

1. Kościół w Persji od III do VII wieku - zarys historyczny. Jak twierdzi Henri-Irénée Marrou (1904-1977) pod koniec III wieku Kościół wschodnich Syryjczyków zaczął organizować się wokół stolicy biskupiej w bliźniaczych „miastach królewskich”, Seleucji-Ktezyfoncie ${ }^{10}$. Kościół perski początkowo podlegał Antiochii. Jednak po ustaniu łączności z Kościołem cesarstwa rzymskiego jego samodzielność rosła. Biskup Seleucji-Ktezyfontu Mar Papa bar Aggai (310/317-329) usilnie starał się o zjednoczenie Kościoła w Persji i jako biskup stolicy ogłosił się katolikosem, co zrodziło opór wielu innych biskupów i doprowadziło do próby złożenia go z urzędu w czasie synodu. Mar Papa miał wtedy poprosić o wsparcie biskupów wschodnich prowincji imperium rzymskiego, uzyskując formalne potwierdzenie pierwszeństwa swojej siedziby biskupiej w Persji ${ }^{11}$. Zdaniem Josepha Yacouba tytuł katolikosa i wikariusza ge-

\footnotetext{
${ }^{4}$ Por. Sozomenus, HE II 10, SCh 306, 274-276, Kazikowski, s. 101.

${ }^{5}$ Por. tamże II 13, SCh 306, 282-284, Kazikowski, s. 105.

${ }^{6}$ Tamże VI 1, SCh 495, 242, Kazikowski, s. 351.

${ }^{7}$ Por. M. Cary - H.H. Scullard, Dzieje Rzymu. Od czasów najdawniejszych do Konstantyna, II, thum. J. Schwakopf, Warszawa 1992, 230, 309 i 314 (pisownia: „Seleukia i Ktezyfon”); zob. też Sokrates Scholastyk, Historia Kościoła, s. 310, przyp. 128.

${ }^{8}$ Por. Cary - Scullard, Dzieje Rzymu, II, s. 365.

${ }^{9}$ Por. tamże, s. 371.

${ }^{10}$ Por. J. Daniélou - H.I. Marrou, Historia Kościoła, I: Od poczatków do roku 600, thum. M. Tarnowska, Warszawa 1984, 180.

${ }^{11}$ Por. A. Baumstark, Geschichte der syrischen Literatur mit Ausschluss der christlichpalästi-
} 
neralnego przejęli następcy Mar Papy począwszy od Mar Symeona bar Sabbe (Mar Shimoun bar Sabbae), który stał na czele Kościoła Mezopotamskiego w latach 329-341 ${ }^{12}$. W połowie IV wieku chrześcijanom w Persji przyszło żyć w bardzo niesprzyjających warunkach społeczno-politycznych. Król Szapur II, jeden z największych władców sassanidzkich, chcąc umocnić potęgę swojego imperium i zdobyć przewagę nad największym wrogiem, Cesarstwem Rzymskim, starał się wykorzystać mazdeizm i uczynił z niego religię państwową. W osiagnięciu tych imperialnych planów przeszkodą była chrześcijańska mniejszość. W drugiej połowie swojego panowania Król Królów wszczął gwałtowne prześladowania Kościoła, zwrócone zwłaszcza przeciw jego strukturom. Trzech kolejnych biskupów Seleucji-Ktezyfontu poniosło śmierć męczeńska, a w latach 348-388 ta centralna siedziba Kościoła w Persji pozostawała nieobsadzona. Gdy prześladowania minęły, odbudową Kościoła perskiego pokierował Marutha (zm. przed 420), biskup Maipherqat (Martyropolis). Hierarcha wykorzystał swoje doświadczenie i znajomości na dworze króla Yazdegarda I (399-420). Ten czwarty następca Szapura II zastosował politykę tolerancji wobec swoich chrześcijańskich poddanych. Wykorzystując sprzyjające warunki, Marutha zwołał w 410 r. do Seleucji synod. Czterdziestu biskupów przyjęło dogmatyczne i dyscyplinarne postanowienia Soboru Nicejskiego (325). Nadto przyjęto porządek i hierarchię w całym Kościele perskim: jeden kościół dla jednej parafii, jeden biskup dla diecezji, jeden metropolita dla prowincji. Zwierzchnikiem zaś wszystkich był ,wielki metropolita i głowa biskupów" rezydujący w Seleucji-Ktezyfoncie. H.I. Marrou wyjaśnia, że tytuł katolikosa otrzymał on później, w latach 421-456. Odbudowany Kościół $\mathrm{w}$ imperium perskim mógł $\mathrm{w}$ ten sposób przygotować się na kolejne prześladowania, jakie go spotkały w V wieku. Dzięki działalności Maruthy można było osadzić biskupów na odległych wyspach Bahrainu w Zatoce Perskiej i w prowincji Horasan (Khorasan), leżącej w Azji Środkowej ${ }^{13}$. Jak zaznacza J. Yacoub, biskupi Kościoła Orientalnego często pełnili niebezpieczną funkcję ambasadorów i emisariuszy tak Cesarstwa Rzymskiego, jak imperium perskiego. Sam Mar Marutha dwukrotnie udawał się z poselstwem rzymskim na dwór Yazdegarda I; również Mar Akacjusz (V w.), biskup Amidy, stawał przed tym perskim królem w charakterze ambasadora imperatorów Arkadiusza (377/378-408) i Teodozjusza II (408-450). Z kolei Mar Yahbalaha I (416-420) był emisariuszem Yazdegarda I w Konstantynopolu w 418 roku. W podobnym charakterze do Konstantynopola wyruszali patriarchowie Mar Ishoyahb I (580-595) w 587 r. i Mar Ishoyahb II (628-645) w 630 r. Dzięki zaangażowa-

nensischen Texte, Bonn 1922, 29-30.

${ }^{12}$ Por. J. Yacoub, Babylone chrétienne. Géopolitique de l'Église de Mésopotamie, Paris 1996, 141.

${ }^{13}$ Por. Daniélou - Marrou, Historia Kościoła, II, s. 217-219. 
niu dyplomatycznemu biskupów Kościół w Persji zyska na znaczeniu i będzie cieszył się większą wolnością ${ }^{14}$.

2. Seleucja-Ktezyfont w Mowach Afrahata, perskiego Mędrca. Z czasów prześladowań Kościoła w Persji pod panowaniem Szapura II, opisanych przez Hermiasza Sozomena, zachowała się jeszcze inna relacja, której autorem jest Afrahat, zwany Mędrcem, rodowity Pers piszący po syryjsku w I połowie IV w. Wśród jego Mów znajduje się List synodalny, umieszczony w kolejności jako czternasta mowa ${ }^{15}$. Jest to pismo skierowane do chrześcijan w Seleucji-Ktezyfoncie, w którym wspomina się o wewnętrznych sporach i rozbiciu w prześladowanym Kościele perskim, o czym nic nie mówił Hermiasz Sozomen. List synodalny zawiera społeczno-religijną ocenę postępowania chrześcijan, zwłaszcza postaw duchowieństwa ${ }^{16}$. Afrahat oskarża pasterzy Kościoła i zarzuca im nadużywanie władzy. Jego oskarżenie wyraźnie sugeruje związki duchownych z urzędnikami państwowymi, które dawały obustronne korzyści. Krytyce poddano postawę interesownej uległości kleru wobec władzy świeckiej. Równocześnie Mędrzec roztropnie apeluje, aby sporów wewnątrzkościelnych nie ujawniać na forum zewnętrznym, zwłaszcza gdy chrześcijanie są prześladowani ${ }^{17}$. W liście brak nazwisk, imion i konkretnych miejsc, jednak dzięki obrazom i biblijnym porównaniom można było bez narażania na denuncjację przed państwowym wywiadem wskazać krytykowanych hierarchów. Najprawdopodobniej wszystkie oskarżenia skierowane pod adresem przywódców duchowieństwa perskiego dotyczyły również Mar Symeona bar Sabba'ei (ok. 329-ok. 341), patriarchy Seleucji i Ktezyfontu ${ }^{18}$. Według Chronica seertensis, dzieła napisanego przez nestoriańskiego autora po arabsku w IX lub w X wieku, Mar Symeon (Shimun bar Sabba) miał być ,pprzyjacielem” Szapura $\mathrm{II}^{19}$ i podobnie jak przywódca gminy żydowskiej cieszył się on krótko pozycją księcia na królewskim dworze, co dawało mu prawo do noszenia diademu. Ten ambitny hierarcha starał się usilnie zdobyć

${ }^{14}$ Por. L.R.M. Sako, Le rôle de la hiérarchie syriaque orientale dans les rapports diplomatiques entre la Perse et Byzance aux V-VII siècles, Texte et Études sur Orient Chrétien 2, Paris 1986, 202.

15 Aphraates, Demonstratio 14 (Exhortatoria), ed. J. Parisot: Aphraatis Sapientis Persae Demonstrationes, PSyr 1, Parisiis 1894 (Reprint: Turnhout 1980), 573-726.

${ }^{16}$ Por. A. Uciecha, Postawa duchowieństwa Kościoła Perskiego w czasie prześladowań Szapura II, w: Vobis Episcopus vobiscum christianus, red. W. Myszor - A. Malina, Katowice 2004, 278-287.

${ }_{17}^{17}$ Por. Aphraates, Demonstratio 14, 7, PSyr 1, 588, 3-13; 14, 25, PSyr 1, 633, 5-26; 14, 25, PSyr 1, 636, 1-8; 14, 26, PSyr 1, 636, 24 - 637, 26; 14, 44, PSyr 1, 708, 1-16 i 23-26; 14, 45, PSyr 1, 709, 12-18 (tekst syryjski i tłumaczenie łacińskie). Przyjęte oznaczenie dostosowane zostało do wydania J. Parisota (por. przyp. 15), gdzie pierwsza cyfra wskazuje na numer Mowy, druga oznacza podział na rozdziały w tłumaczeniu łacińskim, dalsze natomiast wskazują kolejno numery kolumn i wierszy tekstu syryjskiego (PSyr 1).

${ }^{18}$ Por. tamże 14, 8, PSyr 1, 588, 14 - 589, 1.

${ }_{19}$ Por. Chronica Seertensis 27, ed. A. Scher - J. Périer: Histoire nestorienne (Chronique de Séert), PO 4, Paris 1907 (Reprint: Turnhout 1981), 297. 
władzę nad wszystkimi biskupstwami w Persji. Zamierzonego celu nie mógł jednak osiągnąć bez podporządkowania się władzy Króla Królów. Wszystkich zatem buntowników, którzy nie chcieli zgodzić się na taką formę zniewolenia, należało wydać urzędnikom państwowym. Niesubordynacja wiernych również była surowo karana. Wplątany w polityczno-finansowe rozgrywki Mar Symeon najprawdopodobniej padł ofiarą własnej intrygi. Gdy bowiem odmówił płacenia haraczu na rzecz państwa, został skazany na śmierć ${ }^{20}$. Relacja Afrahata jako naocznego świadka prześladowanego i podzielonego Kościoła w Persji IV wieku wydaje się bardziej wiarygodna, choć mniej budująca, niż hagiograficzny przekaz piszącego prawie sto lat później Hermiasza Sozomena. Podobnie pozytywny obraz postawy biskupa Symeona jako męczennika przedstawiony został w Martyrium beati Simeonis bar Sabba' $e^{21}$.

3. Seleucja-Ktezyfont w Synodicon Orientale ${ }^{22}$. Obszerniejszym niż Mowy Afrahata źródłem opracowania tematyki powstania i rozwoju patriarchatu Seleucji-Ktezyfontu w starożytnym Kościele w Persji jest zbiór uchwał synodalnych Synodicon Orientale. Dzieło to przełożył i opatrzył komentarzem Jean-Baptiste Chabot w 1902 roku. Micheline Albert, sugerując się podtytułem wydania J.B. Chabota: Receuil de synodes nestoriens, włączyła Synodicon do grupy pism kanonicznych Kościoła nestoriańskiego i scharakteryzowała jako kolekcję pochodzącą z VIII wieku, a zachowaną w dwóch manuskryptach i zawierającą decyzje 15 synodów, które odbyły się w Seleucji-Ktezyfoncie między rokiem 410 a $790^{23}$. W rzeczywistości zbiór obejmuje akta 14 synodów, odbytych w latach 410-775. Ostatnim z nich jest synod, który miał miejsce za rządów Mar Henanyeshu II (773-780). Poniższego wyboru fragmentów Synodicon dokonano ze względu na próbę przybliżenia historycznych i teologicznych wątków odnoszących się do genezy i rozwoju prestiżu biskupa Seleucji-Ktezyfontu. Należy zaznaczyć, że badany temat tytulatury patriar-

${ }^{20}$ Por. M.J. Pierre, Introduction, w: Aphraate le Sage Persan, Les Exposés, t. 1: Exposés I-X, SCh 349, Paris 1988, 87-88.

${ }^{21}$ Por. Martyrium beati Simeonis bar Sabba'e, ed. M. Kmosko, PSyr 2, Parisiis 1907 (Reprint: Turnhout 1993), 715-778.

${ }^{22}$ Por. Synodicon Orientale, ed. J.B. Chabot: Synodicon Orientale ou Recueil de synodes nestoriens, publié, traduit et annoté d'après le Ms. syriaque 332 de la Bibliothèque Nationale et le Ms. K. VI, 4 du Musée Borgia à Rome, Paris 1902. Tekst również dostępny on-line: http://contentdm.lib. byu.edu/cdm/ref/collection/CUA/id/29422 [sprawdzono: 07.08.2013], jak również niepublikowane ang. tłum. M.J. Birnie: Gesta concilii Mār Yahbalaha (The Synod of Mar Yahbalaha 420 AD): http:// www.fourthcentury.com/the-council-of-mar-yahbalaha-ad-420 [sprawdzono: 07.08.2013]. W języku polskim ukazały się Gesta concilii Mār Aqaqa (Akta synodu Mar Akacjusza [486]) w przekładzie R. Zarzecznego, zob. Dokumenty synodów od 431 do 504 roku, układ i oprac. A. Baron - H. Pietras, SCL 6, ŹMT 62, Kraków 2011, 291-299.

${ }^{23}$ Por. M. Albert, Langue et littérature syriaque, w: Christianismes Orientaux. Introduction à l'étude des langues et des littératures, ed. M. Albert - R. Beylot - R.G. Coquin - B. Outtier Ch. Renoux, introduction par A. Guillaumont, Paris 1993, 370. 
chalnej, kojarzonej z kościelną pozycją „miast królewskich” na podstawie Synodicon Orientale, został przedstawiony w obszernym i wnikliwym studium Luise Abramowski: Der Bischof von Seleukia-Ktesiphon als Katholikos und Patriarch der Kirche des Ostens z $2007 \mathrm{r}^{24}$ oraz w wielu interesujących artykułach i opracowaniach innych orientalistów ${ }^{25}$.

Obrady pierwszego z wymienionych tam synodów toczyły się w styczniu i lutym 410 r. w obecności Yazdegarda I, pod przewodnictwem Mar Izaaka (ok. 399-410) i czujnym okiem Maruthy, biskupa Maipherqat (Martyropolis). Izaak nosi tam następujące tytuły: „biskup Seleucji i Ktezyfontu” ( $290,0,9 \Omega)$, „,ka-

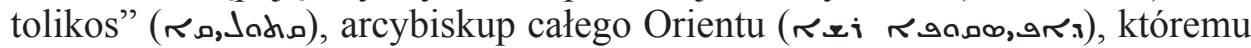

${ }^{24}$ Por. L. Abramowski, Der Bischof von Seleukia-Ktesiphon als Katholikos und Patriarch der Kirche des Ostens, w: Syrien im 1.-7. Jahrhundert nach Christus. Akten der 1. Tübinger Tagung zum Christlichen Orient (Tübingen, 15.-16. Juni 2007), hrsg. von D. Bumazhnov - H.R. Seeliger, Studien und Texte zu Antike und Christentum 62 Tübingen 2011, 1-56.

${ }^{25} \mathrm{Na}$ temat genezy i znaczenia patriarchatu Seleucji-Ktezyfontu, por. O. Braun, Der Briefwechsel des Katholikos Papa von Seleucia. Ein Beitrag zur Geschichte der ostsyrischen Kirche im vierten Jahrhundert, ZKT 18 (1894) 163-182 i 546-565; J. Labourt, Le christianisme dans l'empire perse sous la dynastie Sassanide (224-632), Paris 1904; tenże, Le patriarche Timothée et les nestoriens sous les Abbasides, „Revue d'Histoire et de Littérature Religieuse” 10 (1905) 384-402; M. Streck, Seleucia und Ktesiphon, Leipzig 1917; W. de Vries, Antiochien und Seleucia-Ctesiphon, Patriarch und Katholikos?, w: Mélanges Eugène Tisserant, vol. 3: Orient chrétien, ST 233, Città del Vaticano 1964, 429-450; J.M. Fiey, Les étapes de la prise de conscience de son identité patriarcale par l'Église syrienne orientale, „L'Orient Syrien” 12 (1967) 3-22; W.F. Macomber, The authority of the Catholicos Patriarch of Seleucia-Ctesiphon, w: I patriarcati orientali nel primo millennio. Relazioni del Congresso tenutosi al Pontificio Istituto Orientale (Roma, 27-30 dicembre 1967), OCA 181, Roma 1968, 179-200; C. Müller - G. Detlef, Stellung und Bedeutung des Katholikos-Patriarchen von Seleukeia-Ktesiphon im Altertum, OC 53 (1969) 227-246; J.M. Fiey, Jalons pour une histoire de l'Église en Iraq, CSCO 310, Subsidia 36, Leuven 1970; A. de Halleux, Le symbole des évêques perses au synode de Séleucie-Ctésiphon (410), w: Erkenntnisse und Meinungen II, hrsg. von G. Wiessner, Göttinger Orientforschungen 1, Reihe: Syriaca 17, Wiesbaden 1978, 161-190; M.L. Chaumont, La christianisation de l'Empire Iranien, des origines aux grandes persécutions du IV siècle, CSCO 499, Subsidia 80, Leuven 1988; M. Tamcke, Der Katholikos-Patriarch Sabriso I. (596-604) und das Mönchtum, Frankfurt/Main 1988; W. Schwaigert, Das Christentum in Hüzistân im Rahmen der frühen Kirchengeschichte Persiens bis zur Synode von Seleukeia-Ktesiphon im Jahre 410, Ph.D. Dissertation. Marburg - Lahn 1989; J. Habbi, Synodalité de l'Église d'Orient de Séleucie-Ctésiphon, OC 75 (1991) 91-112; tenże, La structure patriarcale de l'Église, w: Incontro fra Canoni d'Oriente e d'Occidente. Atti del congresso internazionale, a cura di R. Coppola, vol. 1, Bari 1994, 157182; H. Suermann, From the Foundation to Independence: Milestones of the Church of SeleuciaCtesiphon, „The Harp” 16 (2003) 367-370; C. Pasquet, Le synode de Séleucie-Ctésiphon (410). Quelques remarques sur l'ecclésiologie des communautés chrétiennes de Perse au ve siècle, CPE 96 (2004) 44-55; Ch. Jullien, Kaškar „la sublime” et sa singulière prééminence sur le siège patriarcal de Séleucie-Ctésiphon, w: Proceedings of the $5^{\text {th }}$ Conference of the Societas Iranologica Europća (Ravenna, 6-11 October 2003), vol. I: Ancient and Middle Iranian Studies, ed. A.C.D. Panaino A. Piras, Bologna 2006, 543-552; H. Suermann, Bedeutung und Selbstverständnis des KatholikosPatriarchen von Seleukia-Ktesiphon, w: Inkulturation des Christentums im Sasanidenreich, hrsg. von. A. Mustafa - J. Tubach - G.S. Vashalomidze, Wiesbaden 2007, 227-236. 



całego Orientu $(\kappa x m)^{26}$. Co więcej, zdaniem J. Yacouba, Seleucja-Ktezyfont

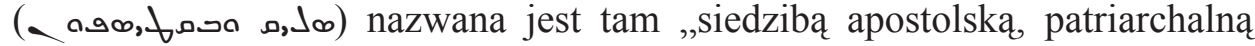
i ojcowską" 27 . Opinia tego badacza na temat patriarchalnej godności miasta jest nieprecyzyjna, a wręcz myląca, gdyż w Synodicon Orientale brak takiego określenia w sformułowaniach synodu z 410 r. 37 biskupów - J. Daniélou podał, że wszystkich 40 - przyjęło 21 kanonów regulujących zasady organizacji Kościoła w Persji i uznało nadrzędną władzę jurysdykcyjną katolikosa Seleucji-Ktezyfontu ${ }^{28}$. Siedzibą katolikosa został kościół Kôkê (ruan) położony na terenie Seleucji ${ }^{29}$. W pierwszym kanonie podkreślono władze nadrzędną katolikosa Selucji-Ktezyfontu, który osobiście potwierdza wybór i święcenia nowego biskupa ${ }^{30}$. Najprawdopodobniej potwierdzenie to polegało na częściowym powtórzeniu ceremonii ordynacji ${ }^{31}$. W kolejnym kanonie stwierdzono, że od każdego biskupa krain Orientu wymagane jest absolutne posłuszeństwo katolikosowi i metropolicie $(\infty, \downarrow$, , 」a. $\mathrm{Ktezyfontu}^{32}$. Metropolita może mianować i ustanowić nowego biskupa, ale W obecności co najmniej trzech innych biskupów ${ }^{33}$. W ostatnim kanonie tego synodu ustalono kolejność metropolitów i biskupów według wielkości miast, w których ci hierarchowie mieli swoje siedziby: na pierwszym miejscu figuruje Seleucja-Ktezyfont. Biskup tej stolicy jest „wielkim metropolitą”, „szefem wszystkich biskupów"34; jako ojciec i przywódca wszystkich metropolitów ma władzę ich mianowania i nakładania rąk; bez jego zgody żaden metropolita nie może objąć stanowiska, ani ważnie pełnić swojej funkcji. Następnie wymienione są stolice metropolii $\mathrm{w}$ porządku pierwszeństwa. Przyjęto również, że w wyborach patriarchy mogli uczestniczyć tylko biskupi należący do owych metropolii ${ }^{35}$. J. Yacoub podkreśla, że model organizacji prowincji w Kościele Mezopotamii nie został podporządkowany ani administracji perskiej, ani też rzymskiej. Katolikos-patriarcha Seleucji-Ktezyfontu był równocześnie metropolitą prowincji Bet-Aramaye (Suristan), która obejmowała Babilonię ${ }^{36}$.

${ }^{26}$ Por. Synodicon Orientale. Gesta concilii Mār Isaac, ed. Chabot, s. 17-18. Najczęściej powtarzającymi się tytułami Mar Izaaka wymienianymi razem są: biskup, katolikos i arcybiskup całego Orientu (por. tamże, s. 18. 19. 20. 30; thum. franc. s. 254. 256. 257. 258. 259. 267. 269).

${ }^{27}$ Tak określa Seleucję-Ktezyfont J. Yacoub (Babylone chrétienne, s. 143).

${ }^{28}$ Por. komentarz J.B. Chabot, Synodicon Orientale, s. 257, nota 1.

${ }^{29}$ Por. Synodicon Orientale. Gesta concilii Mār Isaac can. 6, ed. Chabot, s. 25.

${ }^{30}$ Por. tamże can. 1, ed. Chabot, s. 23; zob. też tamże can. 20, ed. Chabot, s. 32.

${ }^{31}$ Por. komentarz J.B. Chabot,Synodicon Orientale, s. 263, nota 4.

${ }^{32}$ Por. Synodicon Orientale. Gesta concilii Mār Isaac can. 12, ed. Chabot, s. 26.

${ }^{33}$ Por. tamże can. 17, ed. Chabot, s. 30.

${ }^{34}$ Tamże can. 21, ed. Chabot, s. 33; J. Yacoub (Babylone chrétienne, s. 144) dodaje od siebie tytuł „patriarcha”, którego w tekście synodalnym nie ma; podobnie brak w tym miejscu określenia Seleucji-Ktezyfontu héritière Babylone („dziedziczka Babilonu”).

${ }^{35}$ Por. Synodicon Orientale. Gesta concilii Mār Isaac, ed. Chabot, s. 30.

${ }^{36}$ Por. Yacoub, Babylone chrétienne, s. 145-146; na temat pozycji katolikosa Mar Izaaka, zob. 
Cztery lata po drugim zanotowanym w Synodicon Orientale synodzie Mar Yahbalaha I odbył się w 424 r. w Markabta synod Mar Dadyeshu (Dadisho). „Zarządzający całym Kościołem Orientu” Dadisho (421-431) złożył wówczas rezygnację z urzędu katolikosa. Jednak zgromadzeni biskupi błagali swojego przywódcę o pozostanie na ich czele tak, jak Piotr pozostał na czele Apostołów. Wtedy to w tytulaturze metropolitów Seleucji-Ktezyfontu pojawia się po raz pierwszy w Synodicon Orientale termin ,patriarchat” ( Rhan i,ifa. $)$ w wyrażeniu przetłumaczonym na francuski jako ,dar patriarchatu" (le don du patriarcat) ${ }^{37}$.

W uchwałach tego synodu Kościół Orientu pod przewodem katolikosa Seleucji-Ktezyfontu potwierdził swoją niezależność i odrębność od patriarchatu Antiochiii ${ }^{38}$ : Mar Dadyeshu został nazwany „najwyższym przywódcą biskupów i zarządcą wszystkich Kościołów Orientu”, a równocześnie nie musiał już podlegać żadnej zwierzchności „ojców zachodnich”. Jedynie sam Chrystus był jego sędzią. Na synodzie Mar Dadyeshu uchwalono także, że chrześcijanie pozostający pod władzą Seleucji-Ktezyfontu nie będą mogli odtąd skarżyć się na swojego katolikosa przed trybunałem patriarchów Zachodu. W sposób jednoznacznie i definitywnie zarezerwowano rozstrzyganie wszelkich spraw kościelnych biskupowi Seleucji-Ktezyfontu ${ }^{39}$.

Całkowita niezależność jurysdykcyjna tego Kościoła nastąpiła po przyjęciu przezeń doktryny nestoriańskiej potępionej przez sobór w Efezie $(431)^{40}$. Ciekawe wnioski wyciaga na bazie historycznej analizy kanonów synodu z roku 424 Joseph Habbi/Yüsuf Habbî: oto, zdaniem tego badacza, dwa patriarchaty - mezopotamski (Seleucja-Ktezyfont) i ormiański - najlepiej odzwierciedlają rzeczywistość pierwszych wspólnot chrześcijańskich. Były to Kościoły odizolowane z powodów politycznych. Każdy katolikos lub patriarcha był najwyższym zwierzchnikiem oraz ojcem i Piotrem swojego Kościoła ${ }^{41}$.

Około 498 r. potwierdzono to definitywne oddzielenie. Prymat patriarchy Babilonu w Kościele Orientu został porównany do prymatu św. Piotra wśród Apostołów. Pół wieku później, a dokładnie w roku 544, patriarcha Mar Aba I (540-552) przeprowadził kolejną reformę tego Kościoła, umacniając kościelną i polityczną pozycję siedziby w Seleucji-Ktezyfoncie oraz rozwijając jej działalność misyjną. Alberto Camplani podkreśla rosnące znaczenie

\footnotetext{
Habbi, La structure patriarcale de l'Église, s. 180.

${ }^{37}$ Synodicon Orientale. Gesta concilii Mār Dadyeshu, ed. Chabot, s. 44 (thum. franc., tamże, s. 286). Termin ten nie występuje w tekście synodu z 486 r. Pojawia się zaś na synodzie Barsaumy w 484 r. ,prowincja patriarchalna Seleucji-Ktezyfontu” ( $\kappa, n$ i,ito $\kappa, \infty i o n)$, por. Synodicon Orientale. Gesta concilii Mār Barsauma'e, s. 61.

38 Por. J. Féghali, Perspectives sur l'histoire et l'institution des patriarches orientaux, w: Mélanges offerts à Jean Dauvillier, Toulouse 1979, 281.

${ }^{39}$ Por. Synodicon Orientale. Gesta concilii Mār Dadyeshu, ed. Chabot, s. 48-50.

${ }^{40}$ Por. Féghali, Perspectives sur l'histoire, s. 281.

${ }^{41}$ Por. Habbi, La structure patriarcale de l'Église, s. 179-181.
} 
katolikosa Seleucji-Ktezyfontu, którego protektoratowi oddawały się w VI i VII wieku klasztory ${ }^{42}$. Jak uważa J. Yacoub Kościół Orientu, błędnie zwany Kościołem Persji, usiłował znaleźć swoją własną drogę między dwoma wrogimi królestwami. W teologicznej argumentacji nie brakowało opinii, że oprócz czterech apostolskich stolic jest jeszcze jedna - Babilon ${ }^{43}$. Na kolejnym synodzie w 585 r. patriarcha Mar Ishoyahb I wraz z biskupami uchwalili, iż Duch Święty wyznaczył cztery patriarchaty na Zachodzie i piąty na Wschodzie, przy czym wszystkie one $\mathrm{w}$ równym stopniu uczestniczą $\mathrm{w}$ pierwszeństwie posługi św. Piotra i Pawła ${ }^{44}$. To eklezjologiczne uzasadnienie pozycji patriarchy zostało pogłębione na synodzie Mar Henanyeshu II w 775 roku. Piotr został ustanowiony przez Chrystusa przywódcą i ojcem Dwunastu. Stolicą Piotra jest również Babilon. Dowodzono przy tym, że Babilon był Ziemią Święta, która zrodziła Abrahama, ojca wiary, oraz że wiara chrześcijańska tutaj została przyjęta po raz pierwszy ${ }^{45}$.

Analityczno-syntetyczne ujęcie zagadnienia przeprowadzone przez Luise Abramowski wydaje się przekonujące: teologiczne interpolacje wprowadzane do protokołów synodalnych Kościoła Orientalnego należy badać w kontekście kształtowania się systemu metropolitalnego oraz ideologii patriarchatu w Kościele Antiocheńskim ${ }^{46}$. W rozwoju swojej struktury kościelnej i jej teologicznych podstaw Kościół Orientalny podlegał wpływom wzorców Kościoła Zachodniego, starając się udowodnić swoją niezależność, równouprawnienie i bogactwo tradycji.

\section{PATRIARCHATE AND PATRIARCHS OF SELEUCIA-CTESIPHON. THE HISTORY OF THE ANCIENT PERSIAN CHURCH}

(Summary)

The Ancient Persian Church came under the influence of the Latin Church in terms of its church structures as well as its theological foundations. It wanted to prove its independence, equal rights and richness of tradition. Arguments in synodical protocols of the Oriental Orthodox Church should be investigated in the context of developing a metropolitan system and an ideology of patriarchate in the Church of Antioch.Evidence were being presented to support the theory

${ }^{42}$ Por. A. Camplani, The Revival of Persian Monasticism (Sixth to Seventh Centuries): Church Structures, Theological Academy, and Reformed, w: Foundations of Power and Conflicts of Authority in Late-Antique Monasticism. Proceedings of the International Seminar (Turin, 2-4 December 2004), ed. by A. Camplani - G. Filoramo, Orientalia Lovaniensia Analecta 157, Leuven 2007, 295.

${ }^{43}$ Por. Yacoub, Babylone chrétienne, s. 147-148.

${ }^{44}$ Por. Synodicon Orientale. Gesta concilii Mār Ishoyahb I can 29, ed. Chabot, s. 160.

${ }^{45}$ Por. Synodicon Orientale. Gesta concilii Mār Henanyeshu II, ed. Chabot, s. 247.

${ }^{46}$ Por. Abramowski, Der Bischof von Seleukia-Ktesiphon, s. 54-55. 
that Babylon was not only the sacred land, which gave birth to Abraham, father of faith, but also that the Christian faith was accepted there for the first time. 